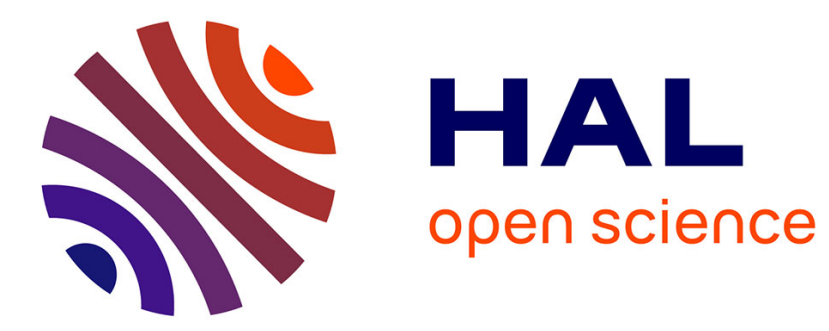

\title{
Knowledge and acceptability of alternative HIV prevention bio-medical products among MSM who bareback
}

\author{
Nuno Nodin, Alex Carballo-Dieguez, Ana M. Ventuneac, Ivan C Balan, \\ Robert Remien
}

\section{To cite this version:}

Nuno Nodin, Alex Carballo-Dieguez, Ana M. Ventuneac, Ivan C Balan, Robert Remien. Knowledge and acceptability of alternative HIV prevention bio-medical products among MSM who bareback. AIDS Care, 2008, 20 (01), pp.105-114. 10.1080/09540120701449096 . hal-00513426

\section{HAL Id: hal-00513426 https://hal.science/hal-00513426}

Submitted on 1 Sep 2010

HAL is a multi-disciplinary open access archive for the deposit and dissemination of scientific research documents, whether they are published or not. The documents may come from teaching and research institutions in France or abroad, or from public or private research centers.
L'archive ouverte pluridisciplinaire HAL, est destinée au dépôt et à la diffusion de documents scientifiques de niveau recherche, publiés ou non, émanant des établissements d'enseignement et de recherche français ou étrangers, des laboratoires publics ou privés. 

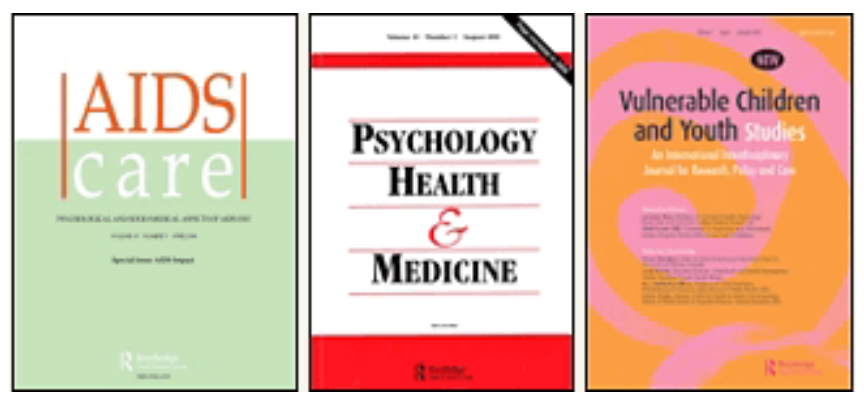

\section{Knowledge and acceptability of alternative HIV prevention bio-medical products among MSM who bareback}

\begin{tabular}{|r|l|}
\hline Journal: & $\begin{array}{l}\text { AIDS Care - Psychology, Health \& Medicine - Vulnerable Children } \\
\text { and Youth Studies }\end{array}$ \\
\hline Manuscript ID: & AC-2006-08-0133.R1 \\
\hline Journal Selection: & AIDS Care \\
\hline Keywords: & HIV prevention, MSM, bareback, internet, qualitative \\
\hline \multicolumn{2}{|}{} \\
\hline
\end{tabular}

\section{S) ScholaroNE" \\ Manuscript Central}




\title{
Knowledge and acceptability of alternative HIV prevention bio-medical products among MSM who bareback
}

\begin{abstract}
Condom use is the best available strategy to prevent HIV infection during sexual intercourse. However, since many people choose not to use condoms in circumstances in which HIV risk exists, alternatives to condom use for HIV prevention are needed. Currently there are several alternative bio-medical HIV prevention products in different stages of development: microbicides, vaccines, post-exposure prophylaxis (PEP) and pre-exposure prophylaxis (PrEP).
\end{abstract}

Seventy two men who have sex with men who took part in a study on Internet use and intentional condomless anal intercourse were asked about these four products during a semi-structured interview. The questions explored knowledge and acceptability of all the products and willingness to participate in microbicide and vaccine trials.

Qualitative analysis of the data suggests that these men had virtually no knowledge of PrEP, very limited knowledge of microbicides, some information about PEP and considerably more knowledgeable about vaccines. Reactions towards the products were generally positive except for PrEP, for which reactions were polarized as either enthusiastic or negative. With the exception of PrEP, many men expressed willingness to use the products in the future. Most men would be willing to participate in trials for microbicides and vaccines if given basic reassurances. Concerns over negative side effects and preoccupation with possible infection were some of the motives given for nonwillingness to participate in a vaccine trial. These results should inform the development of future trials of biomedical prevention products. 


\section{Introduction}

Twenty-five years after the onset of the HIV epidemic, it is clear that reliance on condom use is insufficient to halt the spread of HIV. Researchers have identified multiple factors that lead to either lack of condom use (Pulerwitz et al, 2002; Wong et al, 2003) or incorrect use (De Visser, 2004). Consequently, there is a need to develop alternative HIV prevention methods. Of these, vaccines have been the most publicized; yet, despite considerable effort and investment, no effective vaccine has been developed to date. Other potential HIV-preventive bio-medical approaches are microbicides (both vaginal and rectal), pre-exposure prophylaxis (PrEP) and post-exposure prophylaxis (PEP). Of these, only PEP is available and has been used with some degree of effectiveness (Roland et al., 2005).

Research on knowledge about and acceptability of these products, even before any of them become available, is important for several reasons. First, their availability will not necessarily lead to their use. Experience with vaccines (e.g., Hepatitis B) has shown that availability does not equate widespread use (Jain et al, 2000; Kuo et al, 2004). Similarly, PEP, although available for at least a decade, is not widely known and even general practitioners are not fully aware of its use for non-occupational exposure (Ooi, Dayman \& Yee, 2005). Accordingly, Newman et al (2004) suggest that while these products are not available, its social marketing should be prepared, based upon valid data from research. Second, since large numbers of volunteers will be needed to test the multiple product formulations, it is essential to understand people's motives for participation or nonparticipation in trials and to develop approaches to address potential concerns (Bartholow, et al, 1997; Koblin et al, 1998).

The study of knowledge about and acceptability of these bio-medical products may help the scientific community to develop solutions that address particular needs, interests and 
concerns of populations who do not use condoms. One such population is that of barebackers, i.e., men who have sex with men (MSM) and who choose not to use condoms during anal intercourse (Carballo-Diéguez \& Bauermeister, 2004; Crossley, 2004; Halkitis et al, 2005).

In this article, we analyze knowledge and acceptability of microbicides, vaccines, PrEP and PEP, and willingness to participate in vaccine and microbicide trials among MSM who practice barebacking and who live in the New York City area. Data were drawn from a larger study on Internet use and barebacking.

We begin with a brief description of each product and an overview of related acceptability research.

\section{Microbicides}

Microbicides are presented in formulations such as gels, suppositories or enemas that, when inserted vaginally or anally prior to sexual intercourse, may protect against transmission of HIV and other sexually transmitted infections. Most microbicide acceptability research has been conducted with women with findings indicating a high degree of acceptability (Darroch \& Frost, 1999; Weeks et al, 2004). Much less is known about the women's heterosexual partners, and even less about MSM (Mantell et al., 2005). Among MSM in the United States, one study shows that Latino MSM would be willing to use a lubricant containing a microbicidal solution, given that they already use lubricants during anal sex (Carballo-Diéguez et al, 2000); of these participants, 87\% reported interest in participating in microbicide studies. Another study with 385 MSM in West Hollywood concluded that intention to use microbicides was greater if they had high efficacy and if the man had negative attitudes about using condoms and a history of unprotected anal intercourse (Marks et al., 2000). Thirty-seven percent of the men who always used a condom during anal sex in the past year said they would be more likely to use a 
microbicide gel than a condom in the future, but $85 \%$ of them expected it to provide protection comparable to a condom.

\section{Vaccines}

More than 60 products have been piloted as potential vaccines since the beginning of the pandemic (Kinloch-de Loes, 2004) using different bio-chemical approaches.

Uncertainties over acceptability of a future vaccine, as well as the ongoing need for trial participants, have led to the development of several studies on attitudes and acceptability towards HIV vaccines among diverse populations. In a study conducted in Los Angeles, acceptability of a hypothetical vaccine among MSM was high (Newman et al., 2006).

Efficacy, protection against different types of virus, side effects, and duration of protection were the factors that participants valued the most in such a product.

Studies about willingness to participate in vaccine trials among MSM and other at risk populations have shown that participants in general show interest in taking part in a trial, with greater willingness to participate among those engaging in high-risk behaviors (Bartholow et al., 1997; Hays \& Kegeles, 1999; Koblin et al., 1998) those of older age (Bartholow et al., 1997; Gross et al., 1996) and lower education (Koblin et al., 1998; Bartholow et al., 1997). Altruism is one of the most frequently mentioned reasons for willingness to participate (Hays \& Kegeles, 1999; Koblin et al., 1997; Koblin et al., 1998; Strauss et al., 2001). Frequent concerns among potential research subjects were vaccine safety and vaccine-induced seropositivity (Koblin et al., 1997; Koblin et al., 1998; Strauss et al., 2001). This last factor has kept many potential volunteers from participating in trials. PEP and PrEP

In the mid-1990s, it was discovered that a regimen of anti-retrovirals administered to the mother during pregnancy, labor and delivery, and to her infant during the first six weeks of life significantly reduced the risk of maternal-infant transmission of HIV (CDC, 1994). This 
finding allowed the development of specific HIV prophylaxis for unborn children of HIV positive mothers and later provided the model for prevention of occupational exposure to HIV (e.g. Varghese, Abraham \& Mathai, 2003). Later, the same approach was used in non-occupational exposure to HIV, such as in cases of non-condom use or condom breakage, sexual assault, and needle sharing among injecting drug users. Despite common concerns, research has refuted the idea that PEP may lower inhibitions due to perceived protection, leading to high-risk behaviors (Schechter et al., 2004; Martin et al., 2004).

Maternal-infant prevention of HIV was also used as model for conceptualizing and developing pre-exposure prophylaxis, i.e., administering HIV-specific treatment drugs to HIV-negative individuals, such as sex workers and partners of HIV-positive individuals, that may be at future risk of exposure. Different trials have been conducted, but so far no product is available, despite anecdotal evidence of the use of anti-retroviral medicines to prevent HIV infection in seronegative individuals (Cohen, 2006).

No knowledge or acceptability studies of PrEP were revealed during our literature review.

\section{Methods}

This article is based on data collected from the second phase of a larger study called Frontiers In Prevention (PI: X, PhD) that examined barebacking among men who live in the New York City metropolitan area and who use the Internet to meet sexual partners. This study was approved by the Institutional Review Board of the New York State Psychiatric Institute.

For this paper, we analyzed the interviews that had been transcribed, cleaned of transcription errors and masked for identifiers by February 2006. A total of 72 interviews (out of the total 120 planned) were used for analysis. 


\section{Participant recruitment}

Recruitment was conducted online at six different Internet sites (for a detailed description of the methodology used to identify the sites, refer to X). Potential participants were contacted either by passive methods (entering chat rooms and waiting to be contacted) or by active methods (emailing or sending out instant messages). Recruiters identified themselves as members of a research team and referred potential participants to the study webpage for further information.

Eligible participants had to be male and at least 18 years old; live in the New York City metropolitan area; have had intentional condomless anal intercourse at least once with a male partner met over the Internet; and use the Internet at least twice a month to meet sexual partners. If individuals contacted via email or instant messages indicated an interest in participating in the study, they were screened by telephone and scheduled for a face-to-face, in-depth interview.

A sampling scheme was used to recruit similar numbers of MSM from different ethnic backgrounds, including Latino, European American, African American and Asian or Pacific Islander, and to oversample HIV-negative men.

\section{Procedures}

Informed consent was granted before the face-to-face in-depth interviews, which took place at the New York State Psychiatric Institute, in New York City. All of the interviews were conducted by doctoral level psychologists and audio recorded. Participants were paid $\$ 50$ in cash as compensation for their time. 


\section{Measures}

A semi-structured interview guide was developed specifically for this study to probe participants about Internet use, barebacking, condom use, HIV testing, and non-condom HIV prevention strategies, among other issues. Although the guide had a predetermined structure, it was flexible, allowing the interviewers to follow the natural flow of the information as presented by the interviewee. For that reason, not every single topic or probe was used in every interview.

Analyses for this article include only sections of the interview transcripts that covered noncondom HIV prevention products, including questions and answers about rectal microbicides, HIV vaccines, PEP and PrEP. The first question for each of the products was always "What have you heard about ...". If participants had no knowledge about the product, the interviewer would offer a brief explanation and then continue with subsequent questions. For microbicides and vaccines, participants were also asked if they would be willing to participate in clinical trials.

\section{Analysis}

The initial coding paralleled the structure of the interview guide capturing the major themes. In most cases, the topic of each section of the interview guide was used as a first level code (e.g., the section of the interview on "PEP" was coded as "PEP"). The sections of the transcripts that covered microbicides, HIV vaccines, PEP and PrEP were coded in all the 72 available interviews using QSR NVivo 2.0 software for qualitative analysis. Subsequently, a thorough reading of the material under each code was undertaken to generate sub codes using a bottom-to-top strategy (i.e., based upon the material and not predefined from theory).

\section{Results}




\section{Participants' characteristics}

Of the 72 participants, $28(38.9 \%)$ were under the age of 30 and $44(61.1 \%)$ were 31 and older. Fifteen (20.8\%) were African American; 22 (30.6\%) were European American; 20 (27.8\%) were Latino; 11 (15.3\%) were Asian or Pacific Islanders; and 4 (5.6\%) were of other ethnicity (e.g. Native American or mixed ethnicity).

Forty (55.6\%) were HIV negative; 28 (38.9\%) were HIV positive; and four (5.6\%) were of unknown serostatus. Of the HIV negative participants, 33 (45.8\%) had high-risk behavior for HIV (defined as having receptive unprotected anal intercourse).

\section{Results}

Results are presented first by product and second by main theme to systematize participants' ideas as they emerged during the interviews.

Microbicides

Knowledge

The majority of participants did not know what microbicides were. However, some of them made correct assumptions about the product based solely upon its name.

Microbicides, obviously, is something that kills microbes. And the word rectum means that's where it goes.

Others made incorrect assumptions, often considering it to be an illness.

I would assume [microbicides] are some type of sexually transmitted disease?

Of the minority of participants who had some knowledge about microbicides, most had only superficial information retrieved from outlets such as the Internet or newspapers.

Many participants spontaneously provided some form of analogy when provided 
information about and questioned about their thoughts on microbicides. These analogies were often of Jubricants or spermicides, in particular those with Nonoxynol-9.

It would be great. It's like a woman having a spermicidal cream in her vagina.

Most of those who mentioned Nonoxynol-9 knew that at some point it had been thought to be and used as a potential HIV-prevention agent. Some respondents had actually used it with that purpose. One participant mentioned an episode during the 1980's in which a potential sex partner had suggested using a surgical sterilizing lubricant for anal intercourse as HIV prevention. Other analogies associated microbicides to the contraceptive sponge and PEP.

\section{Reaction to Microbicides}

Most reactions to the concept of a microbicide were positive, ranging from optimistic but contained to enthusiastic. Some participants thought that microbicides' importance would depend upon the ease of its use or its efficacy.

If you make it like electricity, where you don't have to think about it, it's just there when you need it, it'll work. If you can put it in lube, it'll work.

If it works correctly, it would definitely be a good idea.

Several of the participants mentioned that they would use microbicides due to their similarity to lubricants.

You're already using lube anyway when you bareback, so why not have lube that's really protection?

Others were concerned with specific characteristics of the product, such as its consistency, taste or form of use.

I'm not sure the suppository thing would work (...), you're going to have to wait a little bit for that sucker to melt.
Deleted: assumed 
Some participants voiced other concerns, especially about the potential efficacy of a microbicide. In most cases, however, these doubts did not imply a total rejection of the product. For many, proven high efficacy would be a precondition for its use:

I think if somehow it convinced me that this is just as effective as a condom, perhaps, but I don't see how they could possibly make that claim.

Others thought it could promote non-use of condoms and lead to reckless sexual behavior. It's like giving them a green light to bareback

\section{Participation in a trial}

When asked if they would participate in a product trial, the vast majority of participants said they would, for several different reasons.

I like to help science, so yeah, why not?

I'd feel like I've done something for the goodness of homosexuality.

Yes, I'd love to. It'd be a great excuse for me to have sex with people.

Very few participants said they would not volunteer for a trial. In one case this was because the participant was already HIV-positive and couldn't conceive the benefits of his participation. Another one considered himself not to be at high risk and therefore thought his participation would be of little value.

Several said they would be willing to be part of a trial depending on certain conditions, often safety concerns. Some of the participants feared getting infected with HIV during the trials. One worried about inconvenient follow-ups and another one said he would participate only if he was in a monogamous relationship, meaning that it would be easier to follow trial requirements if he had only one sexual partner. 


\section{Vaccines}

Knowledge

The large majority of participants had very general information about HIV vaccines.

I've just heard that there's not one, and they don't work or the one's they've tried haven't worked.

Generally, knowledge came from the news or the Internet. Some participants spontaneously mentioned knowing someone who had participated in trials. Often, participants knew that no effective vaccine exists and that studies are ongoing. A few men were well informed about HIV vaccines, bringing greater detail and depth to their discussion on the issue.

They're in phase I and phase II studies. [I've also heard] that the most likely vaccine to be developed won't prevent you from getting HIV infected, but it will lower the viral load in your system enough that it would be undetectable and non transmittable.

Others had false beliefs, most frequently that HIV vaccines could cause HIV infection or that a vaccine had initially started the HIV epidemic; there was also confusion between the vaccine and anti-retroviral therapy. A few of the participants spontaneously provided analogies to already available vaccines (e.g., smallpox, polio or the flu). All of these analogies carried a positive view about vaccines in general.

\section{Reaction to HIV vaccine}

The majority of reactions to an HIV vaccine were positive, with most participants affirming the need of a vaccine and commenting on how positive it would be to have one.

It's an interesting idea, to be able to get a shot and just be done with it. And that'd be amazing if that actually came around. 
Several said they were hopeful that an effective vaccine will be developed and a few mentioned they would take the vaccine themselves as a prevention strategy, once it became available.

I'm hoping that it would come out of phase III and it would become a success and people could get inoculated and not even become HIV positive.

On the flip side, some participants expressed a mixture of disbelief, suspiciousness and criticism over the pharmaceutical industry, mostly because no vaccine has yet been developed. Some believed that there is already a vaccine or a cure and that it hasn't been released because of interests from companies that are profiting with treatment for HIV positive people. Others thought that a vaccine should already exist given all the investment being made, and others still mentioned their lack of confidence that an effective HIV vaccine will ever be developed.

A small number of participants considered a vaccine to be useless because they were already HIV positive. One mentioned that it might promote barebacking.

Participation in a trial

Of those who were asked whether they would participate in a vaccine trial, most said they would. Some wanted to be helpful and one would be in it for the money. A few participants would only consider volunteering given certain conditions, the most frequent one being having more information about the study.

A few of the participants were not willing to volunteer in HIV vaccine trials. There were three main reasons presented for this: not wanting to be "guinea pigs"; HIV status (being either HIV-positive or -negative were both reasons presented by participants for not considering their participation as valid); and considering it to be a waste of time. 
PEP

Knowledge

When asked if they knew what Post-Exposure Prophylaxis was, the majority of participants answered affirmatively. The depth of knowledge they had about it varied greatly, from fuzzy details to in-depth understanding of how it works and under which circumstances it is supposed to be used.

That is you know that you've been exposed to HIV, that you can take antiretroviral HAART medication, within 72 hours of exposure, you take it for about 30 days and you should come back as being HIV negative.

The origin of the knowledge varied as well. Two participants mentioned they had personal experience with it, while nine other knew someone who had used PEP. Several provided anecdotal details about cases they had heard or read about; others were aware of the fact that it was already used within the medical context. A few participants had known about PEP through an episode of the television series "ER".

Still, many were unaware that such a prevention strategy existed. However, of these respondents, some were able to make correct assumptions about the product, either by associating it to the pregnancy morning after pill or by interpreting its name.

Post-exposure pro--? No, but just from hearing it: afterwards you have sex, something to stop the risk? What's that about?

A small number of participants made incorrect assumptions about PEP. One thought it was only used in medical settings and another actually mistook it for the contraceptive morning after pill. Analogies based upon this product were also mainly with its contraceptive equivalent.

Reaction to PEP 
Most of participants, both the ones who previously knew and the ones who heard about it for the first time during the interview, had favorable reactions to the idea of PEP. The most common reaction was of its acceptance as a valid approach to HIV prevention.

You know, everybody should have some. (laughter) Like you have aspirin! You know, everybody's having sex. Especially if you're having, you know, unprotected sex, then you need to have that in your cabinet.

Some also considered it to be a good wake up call for those who went through it or as a "second chance" situation for someone who made a mistake.

I think it's good emotionally for the individual that they can come to terms with, 'OK, I made a mistake, let me do something right now', and hopefully it's a wake up call.

Several participants said they would use it if they felt the need, for instance, if they knew they had been in a high-risk sexual situation.

I would only use it if I knew I got like perhaps infected or like maybe I was having sex with someone who was seropositive and the condom broke or something like that and they came up my ass.

Others considered it acceptable only in accidental situations or for occasional use, such as in a medical incident or because of lack of condom use due to alcohol or drug abuse.

It's an OK intervention, intervention to use once or twice. OK? Everybody might have a slip up once or twice.

I guess, in the case of accidental like exposure, it would be a good thing.

The most prominent concerns about PEP related to efficacy, negative side effects, and potential use procedures. Some of the efficacy concerns were related to the belief that after the body has been exposed to HIV it is too late to stop the infection. Others were related to the assumed diminished efficacy of PEP when used more than once.

When you start using it two, three, four times a year, how effective is that going to be for 
you?

Concerns with side effects had to do with perceived or known negative effects of the drugs on the body and on daily life. Concerns with use centered on the fact that PEP is a complicated procedure that requires medical counseling. A small number of participants compared it with condoms, which despite being a much simpler prevention method often are not used.

Other negative ideas about PEP were related to perceived high cost and to the thought that it is a way for the pharmaceutical companies to profit. Some of the participants mentioned that PEP could promote barebacking.

I think that [PEP] is bullshit. Because I think that will just encourage all these barebackyou know, the barebacking people. Including myself.

PrEP

Knowledge

In contrast to their more extensive knowledge of PEP, the majority of participants had no knowledge of PrEP. Two, however, made correct assumptions about it based upon what was previously discussed about PEP.

Going based on what you told me just a moment ago, it's the pill - I'm guessing this is the pill you take when you think you're going to have sex, and you don't know whether the person's HIV-positive or not. So you take the pill to make sure that you don't get it? A few other participants made incorrect assumptions about PrEP. One thought it was something that infected people with the virus and another thought it was a condom. Interesting analogies emerged when discussing the concept of PrEP: three participants had heard of or had used antibiotics as a prevention strategy towards other sexually transmitted infections; two compared PrEP with microbicides, since both are supposed to 
be used prior to sex; and one associated it with oral contraception.

\section{Reaction to PrEP}

Reactions to PrEP were more or less evenly distributed between the positive or optimistic responses and the more cautious or unenthusiastic ones. Ease of use was an important feature for those who liked the idea of PrEP.

If you're going out and you know you're going to engage in unsafe sex, (...) I don't think it could hurt, I think it could only help.

That's good also, 'cause if you want to have bareback sex in an orgy or something like that, or in a group, you can take medicine and then you don't have to worry about it.

An HIV-positive participant who was in a relationship with a negative partner stressed that PrEP could be useful in the context of serodiscordant relationships, like his own. Some of the participants said they would use this prevention strategy if it were available.

I would do that. (...) Hell, why not? Let's prepare and have fun.

Less optimistic reactions identified a range of different themes. The most prominent was a concern with side effects. Another important reaction was skepticism towards the concept of PrEP. Participants either considered its availability to be distant in time or had trouble conceiving such a product to be made available at all for political or ideological reasons. Another relevant theme that appeared throughout the interviews was one of concern for efficacy. A few participants thought that PrEP would promote barebacking.

I just think that if you had a pill prior to [sex] it's just going to make you indulge in the behavior more so. So it's kind of like having alcohol and drugs.

This negative perspective on the behavioral effects of PrEP was generally seen more as an attribute of the product itself that would influence men's acts as opposed to a conscious option of the men who would use it. 
Some participants revealed concerns with efficacy and said they would use PrEP only after its preventive effect had been proven.

\section{Discussion}

As expected, participants expressed different levels of knowledge, reactions to and interests in the four products. The analysis reveals several patterns and trends. MSM in our study generally showed high acceptability of alternative non-condom HIV prevention strategies. Participants' reactions to the four products were mainly positive, although with PrEP reactions were polarized between an optimistic response and a more cautious one. Positive reactions to products in general ranged from the hope of seeing them available, particularly vaccines, to the spontaneous affirmation of willingness to use them in the future. Microbicides were most frequently mentioned by participants as a method they would use if it were available. It is likely that this reaction is related both to the perceived easiness of access and of use of the product. In fact, the ease of use of products, like the integration of microbicides in lubricants or the use of a pill prior to sex, were generally valued by these men.

Common negative reactions to all products centered on their presumed efficacy and side effects. It should be noted that these reactions did not imply a total rejection of the products, but were presented as situations under which they would be used conditionally. Given that some of these products may not be fully effective when available, diminished uptake may be a possibility to consider among these men who in fact are at risk and who are some of those for whom these products could be the only HIV prevention strategies used.

A few participants mentioned that availability of all of these products would promote barebacking. This was not a common comment, but nevertheless an interesting one, 
considering that this is a sample of individuals who practice barebacking to some extent. Therefore, their discourses around lack of condom use may mimic those of some of the general population about reckless sexual behavior and need of its stricter social control. It is possible that, despite their engaging in condomless sex, some of these men do not consider themselves to be at risk, for instance due to the practice of serosorting. This practice consists of a selection of sex partners of the same serostatus and has been found to be used by MSM as an alternative protection strategy for those who opt not to use condoms (Cox, Beauchemin \& Allard, 2004; Clatts, Goldsamt \& Yi, 2005; Parsons et al., 2006).

However, it is also possible that some of these men are conflicted with their behavioral choice and split between the will not to use condoms and the risk they acknowledge. This is evident, for instance, by the comment by one of the participants that indirectly criticizes his own reckless behavior and who considers himself to be someone who would use these products as an excuse to bareback. Ambivalent reactions to the products within our sample may therefore reflect those of the barebacking population, thus becoming an obstacle to the uptake of alternative prophylactic strategies towards HIV in the future. Suspiciousness towards the pharmaceutical industry was present in several of the comments about the products. Some men attribute to this industry a dubious and unethical attitude in reference to HIV prevention and treatment. This accounts for part of the negative reactions towards the products and amount to considerable skepticism regarding their development or commercialization in the future. If not addressed, it may also lead to rejection of products when available.

For PrEP, motives for the split reaction to the product were some degree of skepticism about the product and its efficacy, balanced with the perceived advantage of using a pill as a preventive strategy. It seems to be, of all products, the one that will require a greater 
effort, both to promote acceptability and to disseminate among the barebacking MSM population, as not to increase risk behaviors further based upon optimistic and possibly false beliefs about it.

In respect to knowledge, we observed that PrEP was virtually unknown to all participants. Only a few men were aware of the existence of microbicides. Knowledge about PEP was higher, with the majority of participants having some degree of information. The most well Deleted: There was more knowledge on

Deleted: , although the majority of participants were unaware of it

known product was clearly HIV vaccines, with the large majority of participants having heard that a vaccine was under development.

Knowledge of the products appeared to reflect general media exposure about them. From the beginning of the epidemic, HIV vaccines have been discussed and pursued as the account. I ultimate prevention strategy against the virus (Esparza, 2005) and the media, including the gay press, has been broadcasting that to the public. The same has not happened to the same extent with microbicides or PrEP. Nevertheless, in our results, exposure to media was also relevant in the case of PEP knowledge, as some of the participants had known about it from an episode of a television series or read about it on newspapers or the Internet. Anecdotal evidence from contact with someone who had gone through PEP was also important, especially in highlighting negative effects of the prophylaxis.

Different approaches have shown the potential of using the media for sex education interventions (Keller \& Brown, 2002), including among MSM (McOwan et al., 2002). Our results suggest that this may also be true among urban MSM who bareback. Nevertheless, our participants' false beliefs about HIV vaccines, including the idea that the vaccine may cause HIV infection or that a vaccine originally was the cause of HIV spread, also demonstrate that there are problems associated with receiving health information, and especially HIV messages, from mainstream media. Information is not always correct and can result in false beliefs (Cohen, 1994). Our results stress the need for accurate, up-to- 
date information in particular about microbicides and PrEP.

Analogies can be a rich resource for those developing or preparing marketing and dissemination of products that are not yet available (Newman et al., 2004). For instance, explaining PEP using the concept of emergency contraception or associating PrEP with the contraceptive pill can be good options for enhancing the acceptability and uptake of these products among the MSM population in the future, as shown by frequent use of such analogies among our subjects. However, participants often expressed a light approach to some of these products that do not accurately reflect the problems that may be associated with their use. Therefore, special care should also be devoted to highlighting products' possible adverse effects during their promotion.

Most participants would be willing to participate in trials of either vaccines or microbicides whereas others would take part only if given information or reassurance about their safety during the trial. Reasons not to participate were also related to safety concerns. These findings second those of other research (Koblin et al., 1997; Koblin et al., 1998; Strauss et al., 2001) and provide an optimistic perspective of availability of needed at-risk volunteers for ongoing or future trails of these products.

Apparently, interest is high and reactions to microbicides, vaccines, PEP and PrEP are generally positive among MSM in New York City who bareback. This may be due to their infrequent use of condoms and desire for alternative forms of protection from HIV infection. This study jidentified several key ideas and reactions that these men have concerning HIV

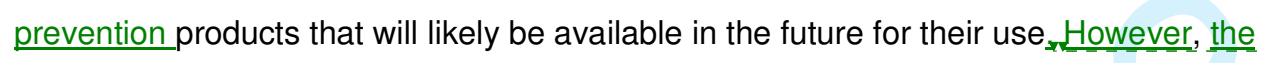
interest that they generally show on the products will not necessarily turn into use.

Deleted: allowed the Deleted: cation of Deleted: and that will allow HIV prevention to some extent without using condoms.

Deleted: Yet

Experience with PEP has shown that availability of a product does not mean that it will be widely known, used or provided by medical personnel. This was evident in our sample, where a significant portion of participants was unaware of PEP, despite frequent sexual 
risk behaviors. Health policies and medical guidelines will be fundamental to delineate what use and profusion specific products will have.

Limitations to these findings are that the data were drawn from a larger study with a different focus than that of this article. Furthermore, not every participant was asked each of these questions during the interviews, thus potentially providing a biased perspective on the issues under analysis. It should also be noted that not necessarily men in cities other than New York or those in non-urban contexts will have similar thoughts on the products under analysis. Nevertheless, we believe to have provided a broad image of the knowledge, thoughts, and reactions that MSM who bareback have towards alternative HIV prevention strategies.

Both quantitative and qualitative research is still needed on PEP and PrEP, where data still seems to be strikingly lacking. Willingness to participate in PrEP trials studies are also needed, especially given recent suspension of ongoing trials due to pressures from HIV activists who accused companies of not providing sufficient health insurance or protection towards participants in the trials (Lange, 2005; Singh \& Mills, 2005). As we hoped to have shown, the barebacking MSM population is diverse and is a potential consumer of these products. Thus more research is needed specifically on the features of the products that may enhance uptake among this population.

\section{References}

Bartholow, B.N.; MacQueen, K.M.; Douglas, J.M.; Buchbinder, S.; McKirnan, D.; \& Judson, F.N. (1997). Assessment of the changing willingness to participate in phase III HIV vaccine trials among men who have sex with men. Journal of Acquired Immune Deficiency Syndromes \& Human Retrovirology, 16(2), 108-15.

Carballo-Diéguez A, Dowsett G, Ventuneac A, Remien R, Balan I, Dolezal C, Luciano O, Lin P. (2006). Cybercartography of popular Internet sites used by New York City MSM interested in bareback sex. AIDS and Education, 18(6), 475-489. 
Carballo-Dieguéz, A.;\& Bauermeister, J. (2004). "Barebacking": intentional condomless anal sex in HIV-risk contexts. Reasons for and against it. Journal of Homosexuality, 47(1), $1-16$.

Carballo-Dieguez, A.; Stein, Z.; Saez, H.; Dolezal,C.; Nieves-Rosa, L.; Diaz, F. (2000). Frequent use of lubricants for anal sex among men who have sex with men: the HIV prevention potential of a microbicidal gel. American Journal of Public Health. Jul;90(7), 1117-21.

Centers for Disease Control and Prevention (CDC)(1994). Zidovudine for the prevention of HIV transmission from mother to infant. Morbidity and Mortality Weekly Report. 43(16),

285-7.

Clatts, M.C.; Goldsamt, L.A.;\& Yi, H. (2005). An emerging HIV risk environment: a preliminary epidemiological profile of an MSM POZ Party in New York City.

Sexually Transmitted Infections, 81(5), 373-6.

Cohen, J. (2006). Protect or disinhibit?. New York Times Magazine, 1.22.06, 30.

Cohen, J. (1994). AIDS and journalism. Trying to tell too clear a story. Integration, (42), 21 2.

Cox, J.; Beauchemin, J.; \& Allard, R. (2004). HIV status of sexual partners is more important than antiretroviral treatment related perceptions for risk taking by HIV positive MSM in Montreal, Canada. Sexually Transmitted Infections, 80(6), 518-23.

Crossley, M.L. (2004). Making sense of 'barebacking': gay men's narratives, unsafe sex and the'resistance habitus'. British Journal of Social Psychology, 43(2), 225-44.

Darroch, J.E.;\& Frost, J.J. (1999). Women's interest in vaginal microbicides. Family Planning Perspectives. Jan-Feb;31(1),16-23.

De Visser, R. (2004). Delayed application of condoms, withdrawal and negotiation of safer sex among heterosexual young adults. AIDS Care. 16(3), 315-22.

Esparza, J. (2005). The global HIV vaccine enterprise. International Microbiology, 8(2), 93101.

Gross, M.; Seage, G.R.; Mayer, K.H.; Goldstein, R.S.; Losina, E.;\& Wold, C. (1996). Interest among gay/bisexual men in greater Boston in participating in clinical trials of preventive HIV vaccines. Journal of Acquired Immune Deficiency Syndromes \& Human Retrovirology, 12(4), 406-12. 
Halkitis, P.N.; Wilton, L.; Wolitski, R.J.; Parsons, J.T.; Hoff, C.C.;\& Bimbi, D.S. (2005). Barebacking identity among HIV-positive gay and bisexual men: demographic, psychological, and behavioral correlates. AIDS, 19(1), 27-35.

Hays, R.B.;\& Kegeles, S.M. (1999). Factors related to the willingness of young gay men to participate in preventive HIV vaccine trials. Journal of Acquired Immune Deficiency Syndromes \& Human Retrovirology, 20(2),164-71.

Jain, N.; Yusuf, H.; Wortley, P.M.; Euler, G.L.; Walton, S.;\& Stokley, S. (2004). Factors associated with receiving hepatitis $B$ vaccination among high-risk adults in the United States: an analysis of the National Health Interview Survey, 2000. Family Medicine, 36(7), 480-6.

Keller, S.N.;\& Brown J.D. (2002). Media interventions to promote responsible sexual behavior. Journal of Sex Research, 39(1), 67-72.

Kinloch-de Loes, S. (2004). Role of therapeutic vaccines in the control of HIV-1. Journal of Antimicrobial Chemotherapy. 53(4), 562-6.

Koblin, B.A.; Avrett, S.; Taylor, P.E.;\& Stevens, C.E. (1997). Willingness to participate in HIV-1 vaccine efficacy trials and the effect of media events among gay and bisexual men in New York City: Project ACHIEVE. Journal of Acquired Immune Deficiency Syndromes \& Human Retrovirology, 15(2),165-71.

Koblin, B.A.; Heagerty, P.; Sheon A.; Buchbinder, S.; Celum, C.; Douglas, J.M.; Gross, M. Marmor, M.; Mayer, K.; Metzger, D;\& Seage, G. (1998). Readiness of high-risk populations in the HIV Network for Prevention Trials to participate in HIV vaccine efficacy trials in the United States. AIDS, 12(7),785-93.

Kuo, I.; Sherman, S.G.; Thomas, D.L.;\& Strathdee, S.A. (2004). Hepatitis B virus infection and vaccination among young injection and non-injection drug users: missed opportunities to prevent infection. Drug and Alcohol Dependence. Jan 7;73(1), 69-78.

Lange, J.M. (2005). We must not let protestors derail trials of pre-exposure prophylaxis for HIV. PLoS Medicine, 2(9), 248.

McOwan, A. ; Gilleece, Y.; Chislett, L.;\& Mandalia, S. (2002). Can targeted HIV testing campaigns alter health-seeking behaviour? AIDS Care, 14(3),385-90.

Mantell, J.E.; Myer, L.; Carballo-Diéguez, A.; Stein, Z.; Ramjee, G.; Morar, N.S.; \& Harrison, P.F. (2005). Microbicide acceptability research: current approaches and future directions. Social Science and Medicine, 60(2), 319-30. 
Martin, J.N.; Roland, M.E.; Neilands, T.B.; Krone, M.R.; Bamberger, J.D.; Kohn, R.P.; Chesney, M.A.; Franses, K.; Kahn, J.O.; Coates, T.J.;\& Katz, M.H. (2004). Use of postexposure prophylaxis against HIV infection following sexual exposure does not lead to increases in high-risk behavior. AIDS, 18(5), 787-92.

Marks, G.; Mansergh, G.;Crepaz, N.;Murphy, S.;Miller, L.C.;Appleby, P.R. (2000). Future HIV prevention options for men who have sex with men: Intention to use a potential microbicide during anal intercourse. AIDS and Behavior, 4(3), 279-287.

Newman, P.A. ; Duan, N. ; Rudy, E.T. ;\& Anton, P.A. (2004). Challenges for HIV vaccine dissemination and clinical trial recruitment: if we build it, will they come? AIDS Patient Care and STDs. 18(12), 691-701.

Newman, P.A.; Duan N.; Lee S.J.; Rudy E.T.; Seiden D.S.; Kakinami, L.; \& Cunningham, W.E. (2006). HIV vaccine acceptability among communities at risk: The impact of vaccine characteristics. Vaccine. 24(12), 2094-101.

Omrani, A.S.;\& Freedman, A. (2005). Prophylaxis of HIV infection. British Medicine Bulletin, In press.

Ooi, C.; Dayan, L.;\& Yee, L. (2004). Knowledge of post exposure prophylaxis (PEP) for HIV among general practitioners in northern Sydney. Sexually Transmitted Infections, $80(5), 420$.

Parsons, J.T.; Severino, J.; Nanin, J.; Punzalan, J.C.; von Sternberg, K.; Missildine, W.;\& Frost, D. (2006). Positive, negative, unknown: assumptions of HIV status among HIVpositive men who have sex with men. AIDS Education and Prevention, 18(2), 139-49.

Pulerwitz, J.; Amaro, H.; De Jong, W.; Gortmaker, S.L.;\& Rudd, R. (2002). Relationship power, condom use and HIV risk among women in the USA. AIDS Care, 14(6), 789-800.

Roland, M.E.; Neilands, T.B.; Krone, M.R; Katz, M.H.; Franses, K.; Grant, R.M.; Busch, M.P.; Hecht, F.M.; Shacklett, B.L.; Kahn, J.O.; Bamberger, J.D.; Coates, T.J.; Chesney, M.A.;\& Martin, J.N. (2005). Seroconversion following nonoccupational postexposure prophylaxis against HIV. Clinical Infections Diseases, 41(10), 1507-13

Schechter, M.; do Lago, R.F.; Mendelsohn, A.B.; Moreira, R.I.; Moulton, L.H.;\& Harrison, L.H. (2004). Behavioral impact, acceptability, and HIV incidence among homosexual men with access to postexposure chemoprophylaxis for HIV. Journal of Acquired Immune Deficiency Syndromes \& Human Retrovirology, 35(5), 519-25.

Singh, J.A.;\& Mills, E.J. (2005). The abandoned trials of pre-exposure prophylaxis for HIV: what went wrong? PLoS Medicine, 2(9), 234. 
Smith, M.J. (2002). Will Vaginal Microbicides Be Acceptable? Network, Vol. 22, 2.

Varghese, G.M.; Abraham, O.C.;\& Mathai, D. (2003). Post-exposure prophylaxis for blood borne viral infections in healthcare workers. Postgraduate Medical Journal, 79(932), 324-8.

Weeks, M.R.; Mosack, K.E.; Abbott, M.; Sylla, L.N.; Valdes, B.;\& Prince, M. (2004). Microbicide acceptability among high-risk urban U.S. women: experiences and perceptions of sexually transmitted HIV prevention. Sexually Transmitted Infections, 31(11), 682-90.

Wong, M.L.; Lubek, I.; Dy, B.C.; Pen, S.; Kros, S.;\& Chhit, M. (2003). Social and behavioural factors associated with condom use among direct sex workers in Siem Reap, Cambodia. Sexually Transmitted Infections, 79(2), 163-5. 